\title{
ABDP: Activity Based Approach to Develop Students Conceptual Understanding of the Course Recycling and Regeneration Technology
}

\author{
Ajinkya K Patil ${ }^{1}$, Pruthviraj C. Chavan², \\ ${ }^{12}$ Assistant Prof., RIT, Rajaramnagar, Islampur and 415414, India. \\ ㄹAjinkyak.patil@ritindia.edu \\ 2Pruthviraj.chavan@ritindia.edu
}

\begin{abstract}
This paper shows an Activity Based Documented Problem Solution (ABDP) concept proficient for coaching for the subject Recycling and Regeneration Technology. For this study, we made two groups like customary group and activated group for study method. This method boost student's understanding. The students undergo ABDP Solution method having extra clear gain of the topic compared to the students undergo topic with regular teaching. Results from t-tests of autonomous samples shown that, as differing to students in customary classes, students in this classes have much additional effective outlooks toward the obedience while impassive comparable performances.
\end{abstract}

Keywords:activated group, customary teaching, ABDP, learning.

\section{Introduction:}

Useful bests and researchers reach to the decision that teachers have a significant impression on students accomplishment. An research from the Texas Schools Scheme, found that brilliance differences clarify the major portion of the variation in analysis. teacher and Other research has revealed that an unproductive teacher can change student learning for reading Other research has shown that an ineffective teacher can impact student learning for years The teacher essentials to understand the instruction aids that are quantitatively proven to impact a teacher's execution in the lecture hall. Here one of the coaching skills that are ABDP solution has found effective to improve student knowledge level such as, creating a knowledge atmosphere, carrying effective teaching and environmental experience as shown in photo \#1. Tremendously operative teaching wants a strong compassionate of a given topic or concept in addition to the thoughtful of how to best communicate the message for that topic. In order to convey positive instruction, student needs to provide illustrious knowledge openings. Altered educational applies need to be incorporated to check students sympathetic. Students should feel engaged in the task and have the opening to take in facts based on their knowledge style. Once the teacher signs that a student may gain from a different knowledge style. The instructor should provide the appropriate kind of task and check for sympathetic. It's important to provide the best learning participation for both teacher and student. There should be an approach which preserves the students.

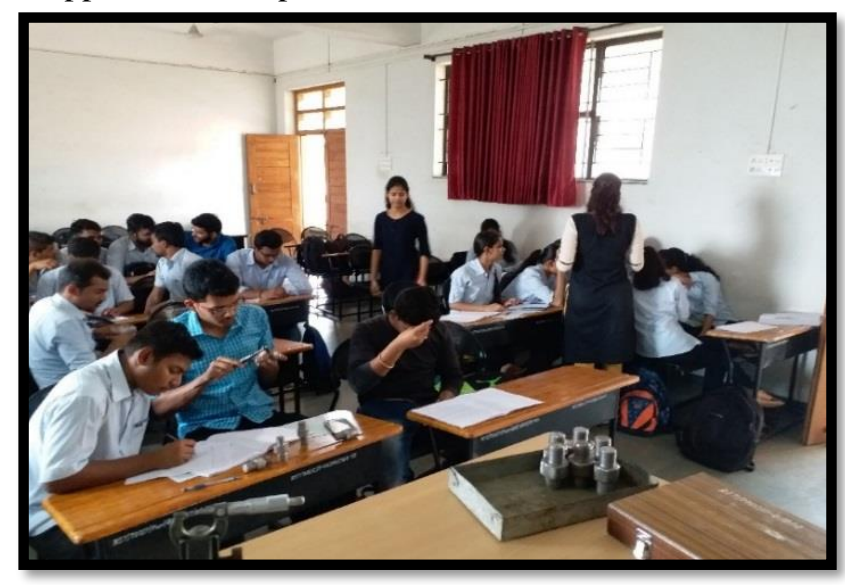

Photo\#1 ABDP Solution

\section{Relatedwork:}

Lecturers and tutor at various universities, counting the University of British Columbia, theUniversity of Memphis, the University of NorthCarolina, Chapel Hill, Texas A\&M University,Capital University, Georgia Institute of Technology and HarveyMudd College have started incorporatingelements of the different model into theirclasses. (J. Yarbro et al., 2013) summaries the empiricalevidence from these endeavours, documenting theimpact on student achievementand engagement.

The capability to engage students and grow criticalthoughtfulskills is presented in (C. F. Herreid and N.A.Schiller, 2013). Kathleen Fulton (Kathleen Fulton,2012) listed the advantages of the ABDP:

1. Students travel like shopfloor.

2. Performing activities on ground gives teachers better understanding into student complications and knowledge styles.

3. Teachers also gets field experience. 
4. Classroom becomes shopfloor

5. Instructors by means of this technique statement seeing increased stages of student attainment, concentration, and assurance.

6. New approaches for accepting theory.

\section{Methodology:}

\section{A. Objectives:}

The objectives of ABDP solution are,

1. To clear the concepts of types of wastes and their properties.

2. To narrate the information for identify and then for calculating actual energy content.

\section{B. What is ABDP solution?}

ABDP solving is an active learning assessment technique that "prompt students to energetically participate and keep track of the steps they take in solving a problem" and then to write down document.

ABDP solution is a pedagogical method in which direct instruction moves from the cluster

Learning space to the separate learning space, and the subsequent group space is converted into a exciting, communicating learning environment where the educator guides students as they apply concepts and engage imaginatively in the subject stuff.

ABDP is an instructional approach and a type of merged learning that reverses the customary learning environment in to field operational learning. In ABDP solution, faculty is going to explain concept and activity that is used fort the same. Students then plays the activity as per instruction, all observations are collaborate in standard format for report and engage in concepts in the classroom with the guidance of a mentor.

Purpose of Technique,

- It allow to view students' thought processes

- Promotes the development of students' problemsolving skills.

- Provides decisive assessment regarding student mistakes and missed steps.

- It allows to provide detailed feedback to students.

- Focuses on the process .(or the correct answer)

\section{Customary vs. ABDP teaching:}

In the customary model of teaching space instruction, the teacher is the essential emphasis of an object lesson and the primary disseminator of information during the period .In a classroom with a established style of instruction, individual lessons may be focused on an clarification of content utilizing a lecture-style. Student engagement in the traditional modelmay be limited to activities or task designed by the teacher. Class discussions are cantered on the teacher, who controls the flow of the conversation (Ryback,D.\&Sanders, J.,1980).
The ABDP solution deliberately shifts teaching to an experiential field model in which periodtime travels topics in superior penetration and creates significant learning openings.In an ABDP, content delivery may take a variety of forms. Often, video teachings prepared by the instructor or third parties are used to deliver content, although online collective conferences, digital research, and text readings may be used (Abeysekera et al., 2015, Ronchetti , 2010 \& Greg Topp ,2011). Students will have debates, activities in the class; based on the videos lessons learned outside the class.

\section{Experimental Detail:}

\section{Experimental set-up:}

The ABDP solution is implemented for third year mechanical engineering students for the elective subject Recycling and regeneration technology. The challenge to the students in the subject is to memorize number of protocols. Students can apply the error finding and correction techniques when students understand it. The level higher than recall in bloom's taxonomy (from recall to apply) is accomplished through ABDP solution. The trial is carried out for a group of 30 students. Based on prior understanding test, group of 30 students are divided into equal group of 15 students. Thus 2 groups are formed which confined equal psychological potential of students. The groups formed are called, customary group and activated group. 


\section{A. ResearchDesign:}

The research design flowas shown in fig. 1

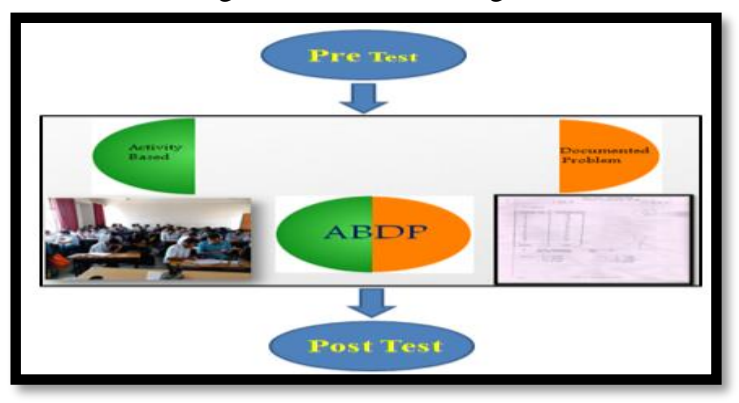

Fig. 1: Research Design

Regulator group is pickled with usual teaching for the areas on Types of waste, properties, energy content of waste linked in educational buildings. Whereas, to the experimental group is provided with the ABDP solution and permitted them to go through the method. The student can play an activity and write report till they understand it. In the classroom, the discussion was held with experimental group and the students in the group can get clarified their doubts in the class.

\section{B. Post Test:}

The equal of sympathetic is analyzed of two groups by taking post-test. Both the groups' regulator group and investigational group made to challenge same problems on the selected topics for investigation and then it is observed with comparative results.

Some sample questions asked in posttest are given below,

1. What are different steps in calculating energy content of waste? (Recall Level)

2. Compare between different types of waste. (Understand Level)

3. Find \%waste available in mechanical building. (Apply Level)

The observations are that,

1. The questions at recall level are attempted well by both groups.

2. But experimental group performed well than control group for the questions which are at understand and apply level.

Hence experimental group students scored more marks in posttest compared to control group students.

\section{Feedback}

At the end of the activity the feedback is conducted from activated group as shown in table 1. This feedback will indicate the students' understanding of the concepts and willingness for the active learning strategy.
Table 1: Feedback

\begin{tabular}{clcccc}
\hline $\begin{array}{l}\text { Sr. } \\
\text { no. }\end{array}$ & Particular & $\begin{array}{c}\text { Poor } \\
(\boldsymbol{\%})\end{array}$ & $\begin{array}{c}\text { Fai } \\
\mathbf{( \% )}\end{array}$ & $\begin{array}{c}\text { Good } \\
(\boldsymbol{\%})\end{array}$ & $\begin{array}{c}\text { Excell } \\
\mathbf{\text { ent }} \\
(\boldsymbol{\%})\end{array}$ \\
\hline 1 & $\begin{array}{l}\text { To what } \\
\text { gratified you } \\
\text { recognize } \\
\text { practical } \\
\text { content? }\end{array}$ & 2 & 8 & 45 & 48 \\
2 & $\begin{array}{l}\text { Is it made you } \\
\text { more attractive? } \\
\text { Whether it } \\
\text { helped you to } \\
\text { increase } \\
\text { understanding } \\
\text { level? }\end{array}$ & 0 & 16 & 47 & 40 \\
4 & $\begin{array}{l}\text { Have you liked? } \\
\text { Would you } \\
\text { indorse similar } \\
\text { session for other } \\
\text { topics? }\end{array}$ & 0 & 6 & 35 & 45 \\
\hline
\end{tabular}

\section{Result Analysis:}

The post test is conducted for both groups control and experimental group. The marks obtained are plotted for in Fig. 2. From the plot shown in Fig. 2 it is clear that higher marks are achieved by activated group compared to customary group.

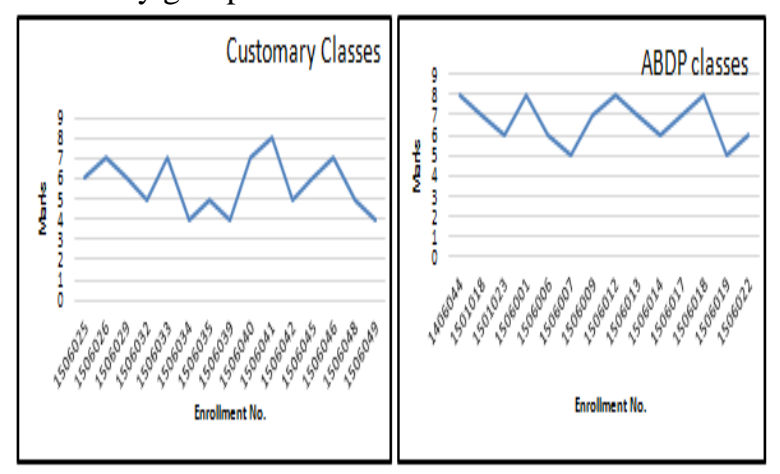

Fig. 2: Post Test Results

Two sets of data are suggestively dissimilar from each otherdetermined by T-Test. The p-value measures homogeny between the results essentially obtained in the trial and the "uncontaminated coincidental" explanation for the results. P-value provides an indication for the noteworthy results obtained by comparison of two groups (Ronald A.Thisted ,2010\& Luc Demortier,2007).

Table 2: Statistical Analysis using t-Test Result

\begin{tabular}{cccc}
\hline T -value & $\begin{array}{l}\text { Standard } \\
\text { Deviation }\end{array}$ & $\begin{array}{l}\text { Degrees of } \\
\text { Freedom }\end{array}$ & $\mathbf{P}$ - value \\
\hline 2.95 & 1.05 & 28 & 0.005 \\
\hline
\end{tabular}

*The result is substantial at $\mathrm{p}<0.05$

\section{Conclusion:}


This paper presented an experience clarification about the use of ABDP Solution for subject Recycling and regeneration technology for third year engineering students. The p-value and t-test results shown in Table 2 designate that, the marks obtained in the post test by investigational group are clearly higher than the marks obtained by regulator group. This means that the investigational group students reached the higher level of bloom's taxonomy i.e., apply level compared to regulator group students. Whereas, few of regulator group students reached to understand level and other are at recall level only. From the feedback obtained by experimental group students, it is found that students' are engaged in the activity and enjoyed the ABDP classroom activity. Hence, ABDP solution can be the enhanced choice than traditional teaching for students' active contribution in learning and hence in turn improving students' learning.

\section{Acknowledgement}

We would like to express our gratitude to RIT, Islampur for providing the necessary facility required to implement an ABDP solution Also, we would like to thank our beloved Director, Dean Academic, HOD of Mech., and our colleagues for their constant support which helped us to implement this practices.

\section{References:}

[1]R. R. Mergu, et. al.,Flipped Classroom Strategy to Improve Students'Learning of Computer Communication Network: An Experience Report, Journal of Engineering Education Transformations,2017, pp. 97-102.

[2]N. Vernadakis, et. al.,Comparing hybrid learning with traditional approaches on learning the MicrosoftOffice Power Point 2003 program in tertiary education,Computers \& Education, Elsevier,2011, pp. 188-199.

[3]L. Botet. al.,'Learning by doing': a teaching method for active learningin scientific graduate education,European Journal of Engineering Education, 2005, pp. 105-119.

[4]M. Killian and H. Bastas, The Effects of an Active Learning Strategy on Students' Attitudes and Students' Performances in Introductory Sociology Classes, Journal of the Scholarship of Teaching and Learning, 2015, pp. 53-67.

[5] S M Naik et. al.,Exploring Team Based Learning PedagogyforMachine Drawing Course, Journal of Engineering Education Transformations,2018, pp. 69-74.

[6] S Binani and R Chowdary, Enhancement of Learning Levels in Engineering Chemistry through Effective Use of Tutorials, Journal of Engineering Education Transformations , 2018, pp. 3136.

[7] MNamrathaet. al.,Active Learning Approach for Python Programming, Journal of Engineering Education Transformations, 2018, pp. 15-19.

[8] H-R Parket. al.,Effects of team-based learning on perceivedteamwork and academic performance in ahealth assessment subject, Collegian, 2015, PP. 299-305. 